Artigo original

Hegemonia - Revista Eletrônica do Programa de Mestrado em Direitos Humanos, Cidadania e Violência/Ciência Política do Centro Universitário Unieuro

ISSN: $1809-1261$

UNIEURO, Brasília, número 24, Julho a Dezembro de 2018, pp. 93-109.

Recebido em: 6/1/2018

Avaliado em: 27/2/2018

Aprovado em: 20/3/2018

\title{
AS POLÍTICAS PÚBLICAS DE REDUÇÃO DA VIOLÊNCIA NA COLÔMBIA
}

Otávio Guimarães Munhoz e Carlos Ugo Santander²

RESUMO: O artigo oferece uma série de conceitos e práticas para políticas públicas buscando resolver o problema de segurança em espaços urbanos, mesclando ações multidisciplinares nos diversos campos do poder público, através de uma abordagem epidemiológica para compreender os motivos da violência. Para isso, apresenta um histórico da violência na Cidade de Medellín, Colômbia, e a partir deste ponto, utiliza os métodos científicos para avaliação da intensidade e organização da violência em Medellín, destacando a sua transformação ao longo do tempo. $\mathrm{O}$ artigo chama a atenção para o número e tipos de atores armados na cidade, bem como as suas motivações, organização e relacionamentos. Por fim, analisa algumas das políticas públicas empregadas com o objetivo de combater a violência urbana e conclui com algumas sugestões para uma intervenção eficaz.

PALAVRAS-CHAVE: Políticas Públicas, Violência Urbana, Medellín, Colômbia.

ABSTRACT: The article offers a lot of concepts and practices for public policies seeking to address the problem of security in urban spaces, by merging multidisciplinary actions in the various fields of public power, through an epidemiological approach to understand the reasons for violence. In doing so, it presents a history of violence in the city of Medellín, Colombia, and from this point on, uses scientific methods to the assessment of intensity and organization of violence in Medellín, highlighting its transformation over time. The article draws attention

\footnotetext{
${ }^{1}$ Mestrando em Direitos Humanos pela Universidade Federal de Goiás.

2 Doutor em Ciências Sociais e docente da Universidade Federal de Goiás.
} 
Artigo original

Hegemonia - Revista Eletrônica do Programa de Mestrado em Direitos Humanos, Cidadania e Violência/Ciência Política do Centro Universitário Unieuro

ISSN: $1809-1261$

UNIEURO, Brasília, número 24, Julho a Dezembro de 2018, pp. 93-109.

to the number and types of armed actors in the city, as well as their motivations, organization and relationships. Finally, it analyzes some of the public policies used to combat urban violence and concludes with some suggestions for effective intervention.

KEYWORDS: Public Policies, Urban Violence, Medellín, Colombia.

\section{INTRODUÇÃO}

A violência tem estado presente nas sociedades humanas desde o início da civilização. Guerras e genocídios fazem parte da história humana. Só muito recentemente é que a questão de evitar esses atos tem sido estudada.

Hoje é possível identificar a violência como uma emergência de saúde pública. Atualmente, a prevenção da violência não só está nas primeiras páginas dos jornais, mas também é um dos principais temas das política públicas.

Uma problema como a violência urbana, pode ser visualizada de forma semelhante a uma doença comum. Os seres humanos, como a maioria dos animais são instintivamente agressivos, no entanto, existem outros fatores que podem alterar o resultado deste instinto, como comportamentos culturais e religiosos, o consumo de álcool, entre outros.

Nos mesmos moldes que estudos científicos podem auxiliar na redução de doenças cardiovasculares através da redução dos fatores de risco, como redução do consumo de gorduras saturadas, mudança de hábitos, como exercício e redução do tabagismo. Eles também podem ser utilizados para alterar fatores de risco da violência.

A violência já foi considerada como domínio exclusivo do sistema de justiça e da polícia. Hoje os cientistas sociais, políticos e outros especialistas estão interessados nesta questão. A estratégia de saúde pública de controlo de fatores de risco para reduzir a doença tem sido aplicada com êxito no caso da segurança pública. $O$ uso de conceitos de 
Artigo original

Hegemonia - Revista Eletrônica do Programa de Mestrado em Direitos Humanos, Cidadania e Violência/Ciência Política do Centro Universitário Unieuro

ISSN: 1809-1261

UNIEURO, Brasília, número 24, Julho a Dezembro de 2018, pp. 93-109.

epidemiologia como multi-causalidade, complexidade das causas e o conceito de fatores de risco podem também contribuir para o controle da violência.

Há mais de duas décadas, prefeitos e ativistas vêm apoiando medidas inovadoras de prevenção da criminalidade e promoção da segurança na América Latina. No entanto, poucos desses esforços se baseiam em evidências. Além disso, as lições tiradas dessas experiências não costumam ser incorporadas em práticas futuras.

Apesar dessas lacunas, governos municipais têm dedicado recursos consideráveis ao financiamento de um largo espectro de programas e políticas para a redução da criminalidade.

Poucos países sofreram tão intensamente com a violência e de forma tão prolongada no século passado quanto a Colômbia. O país atravessou uma guerra civil ao longo das décadas de 1940 e 1950, período que ficou conhecido como "La Violência".

Desde os anos 1960, o país foi tomado tomada por um conflito entre inúmeros grupos de guerrilha de esquerda contra grupos paramilitares de direita e forças militares e policiais. $\mathrm{O}$ conflito ganhou amplitude com a produção e tráfico de cocaína e heroína e desde os anos 1970: as taxas de homicídio e vitimização aumentaram em quase 160\% em menos de 10 anos, entre 1985 e 1995.

A Colômbia se tornou uma importante referência no campo da prevenção e da redução da violência urbana. Em um processo que envolveu uma mudança da cultura de "controle" para a da "prevenção", esforços nacionais e metropolitanos (em parcerias com o meio acadêmico e o setor privado) contribuíram para intensificar e regularizar a redução dos índices do crime. Em 2015, a Colômbia registrou 22,8 homicídios por 100.000 habitantes - a taxa mais baixa em 30 anos.

A violência pode ser classificada de várias maneiras. Ela pode ser classificada de acordo com a pessoa que sofre, como a violência contra as crianças, mulheres, idosos, etc. Ela pode ser classificada de acordo com a aparente motivação, como em racial, política, etc. Também 
Artigo original

Hegemonia - Revista Eletrônica do Programa de Mestrado em Direitos Humanos, Cidadania e Violência/Ciência Política do Centro Universitário Unieuro

ISSN: $1809-1261$

UNIEURO, Brasília, número 24, Julho a Dezembro de 2018, pp. 93-109.

podem ser classificada de acordo com a natureza da agressão, como física, psicológica, sexual, etc. Nenhuma destas classificações é melhor que a outra. Cada uma serve a um propósito específico.

Existem duas categorias de violência que têm valor prático para fins de saúde pública: violência intencional e não intencional. Na primeira estão incluídas aquelas lesões resultantes de um ato deliberado para produzir lesões e morte. Já a segunda categoria incluí acidentes como os automotivos. Ambos os tipos de violência, intencional e não intencional, tem causado preocupação política recentemente.

Para fins de saúde pública, a violência pode ser definida como o uso (ou a ameaça de uso) da força física com a intenção de causar dano a si mesmo ou aos outros. Os dois componentes-chave desta definição são a força física e a intenção de produzir dano. Como pode ser facilmente deduzido, essa definição exclui outras formas de violência, como o psicológica ou sexual, que pode ter especial importância em certos ambientes.

Apesar desta limitação, a definição acima de violência é conveniente porque pode ser facilmente recolhida a partir deformas tradicionais de coleta de informações, como os registros de morte e ferimentos. A violência foi visualizada como a expressão de diversos e complexos processos sociais que produzem homicídios ou lesões. Como consequência, não é possível encontrar uma única causa que poderia explicar a violência completa de uma cidade.

Sendo assim, as iniciativas de prevenção da violência devem ser baseadas em pesquisas científicas. Para isso, é preciso que haja informações sobre os aspectos descritivos da violência na cidade, como os perfis do vítimas e agressores e as circunstâncias específicas em que os crimes ocorreram. A contribuição da droga, do tráfego e criminalidade organizada à violência da cidade deve ser tabelado. Para isso, deve ser criado um sistema para fornecer informações precisas e oportunas sobre os crimes. 
Artigo original

Hegemonia - Revista Eletrônica do Programa de Mestrado em Direitos Humanos, Cidadania e Violência/Ciência Política do Centro Universitário Unieuro

ISSN: $1809-1261$

UNIEURO, Brasília, número 24, Julho a Dezembro de 2018, pp. 93-109.

A partir da análise dos dados incluir os cidadãos e a sociedade como um todo na participação dos esforços para reduzir a violência. Assim, passa a se considerar a violência e o crime demasiados importantes para ser deixado somente nas mãos da polícia e dos militares.

Sendo assim, o objetivo é identificar as mudanças de abordagem, de iniciativas repressivas, focadas no estrito cumprimento da lei e da ordem, que enfatizam a colaboração entre diferentes setores da sociedade.

Identificar se a regulação da cultura é um dos fatores que regula o impulso agressivo humano. Verificar se o consumo de álcool é associado com um aumento em homicídio e suicídio. Analisar a influência das armas de fogo como um fator de risco para a violência. Para diferenciar um conflito armado de outras situações de violência é necessário para determinar se o confronto chegou a um nível mínimo de intensidade, isto é, um "limiar" ou depósito ponto. Para isso, os indicadores quantitativos e qualitativos, são:
a. A duração da violência armada;
b. O número, duração, tipo de confrontos;
c. Os tipos de armas utilizadas;
d. O número e calibre de armas;
e. O número de atores envolvidos;
f. Os níveis de destruição; e
g. As taxas de deslocamento.

É importante salientar que Medellín possui um histórico de violência, pelo menos desde a década de 1980. A ligação entre a dinâmica exógenos (conflitos nacionais por exemplo, e o mercado de narcóticos e outras mercadorias ilícitas) e recursos endógenos (por exemplo, as relações entre grupos armados locais com comunidades, atores armados convencionais e organizações criminosas) têm profunda relação com a intensidade da violência na cidade. $\mathrm{Na}$ verdade, é necessário diferenciar quatro fases de violência armada na cidade: 
Artigo original

Hegemonia - Revista Eletrônica do Programa de Mestrado em Direitos Humanos, Cidadania e Violência/Ciência Política do Centro Universitário Unieuro

ISSN: $1809-1261$

UNIEURO, Brasília, número 24, Julho a Dezembro de 2018, pp. 93-109.

a. Violência dos cartéis da droga com a penetração gradual de grupos guerrilheiros (19891998);

b. A ascendência dos paramilitares mais de guerrilheiros e a militarização da resposta do Estado (1998-2003);

c. Disputas intra-paramilitares e a desmobilização dos paramilitares (2012-2008);

d. Disputa pelo controle da Oficina de Envigado e a entrada de Los Urabeños (2008-2012);

Além disso, é preciso usar o critério de "intensidade", e também examinar frequentemente se há um nível mínimo de "organização" nos atores armados. Para isso, pode ser determinado as características organizacionais com base em indicadores como:

a. a existência de estrutura de comando e as regras e mecanismos disciplinares;

b. a existência e uso de sede;

c. a exibição de controle sobre determinado território;

d. o pronto acesso a armas, equipamentos e treinamento militar;

e. a capacidade de planejar, coordenar e executar as operações militares;

f. a definição de uma estratégia militar unificado;

g. uma capacidade de falar a uma só voz; e

h. a capacidade de negociar cessar-fogo / acordos de paz.

O presente trabalho pretendeu verificar através de uma metodologia mista que envolveu ambos os aspectos qualitativos e quantitativos. É importante salientar que grande parte da informação é baseada em fontes disponíveis ao público, e que as entrevistas foram realizadas em Bogotá e Medellín, de forma voluntária.

E, embora o acesso direto não foi possível, os estudos apontam que as equipes de pesquisa entrevistaram líderes comunitários, organizações da sociedade civil e outras agências humanitárias em Medellín, as quais apresentam um contato direto com as comunidades onde o estavam sendo administrados os programas. 
Artigo original

Hegemonia - Revista Eletrônica do Programa de Mestrado em Direitos Humanos, Cidadania e Violência/Ciência Política do Centro Universitário Unieuro

ISSN: $1809-1261$

UNIEURO, Brasília, número 24, Julho a Dezembro de 2018, pp. 93-109.

Enquanto isso, o trabalho de campo qualitativo, em Medellín, foi realizado ao longo de um período de 17 dias. Um total de 23 informantes foram entrevistados, incluindo representantes do governo local, acadêmicos, organizações não governamentais, líderes comunitários e organizações sociais.

Localizada na Colômbia, a cidade de Medellín conta com quase 4 milhões de habitantes e ganhou fama mundial por ter dado origem a um dos cartéis de drogas mais poderosos da história, o Cartel de Medellín, e a um dos traficantes mais violentos já vistos, Pablo Escobar.

As mudanças no perfil da violência são notadas não apenas em Medellín, mas na Colômbia como um todo, começaram a surgir no início da década de 90, quando poderes municipais passaram a ter papeis mais fortes de monitoramento das atividades policiais.

Do lado da polícia, foi preciso apostar na mudança na forma como oficiais interagiam com a população. Além disso, em 1994, por exemplo, 7 mil policiais envolvidos em casos de corrupção e abusos foram demitidos.

Mas tudo isso foi ainda combinado com uma estratégia chamada "arquitetura social", que envolveu investimentos na recuperação de espaços públicos, especialmente nos bairros mais pobres, e a construção de escolas e bibliotecas por toda a cidade. Como resultado, o país hoje tem a menor taxa de homicídios registrada nos últimos 12 anos (22,8 para cada 100 mil habitantes) e Medellín conta com uma taxa de 19 homicídios para cada 100 mil habitantes. Em 2002, esse número era de 177 para cada 100 mil.

No início dos anos 1990, a taxa de homicídio de Medellín, segunda maior cidade colombiana, era de 360 por 100 mil habitantes. Entende-se o que significa isso comparando com a cidade de São Paulo, onde ela é de 25 por 100 mil, ou seja, 14 vezes menor. A cidade colombiana era centro de operação do narcotráfico e seus assassinos profissionais mesclavamse com diferentes organizações guerrilheiras de esquerda, grupos paramilitares e gangues de adolescentes. Resultando no nada honorífico título de "capital mundial da violência". 
Artigo original

Hegemonia - Revista Eletrônica do Programa de Mestrado em Direitos Humanos, Cidadania e Violência/Ciência Política do Centro Universitário Unieuro

ISSN: $1809-1261$

UNIEURO, Brasília, número 24, Julho a Dezembro de 2018, pp. 93-109.

É um caso bem mais profundo do que o ocorrido em Nova York, onde um ex-prefeito (Rudolph Giulianni) chegou a ser cogitado como ganhador do Nobel da Paz pela redução dos índices de homicídio, atualmente em 7 por 100 mil habitantes. Além de Medellín ter a multiplicidade de fontes de violência de narcotraficantes, gangues de jovens, guerrilheiros e paramilitares, há os indicadores sociais, típicos latino-americanos.

O símbolo máximo do caos era a Comuna 13, um conglomerado de 25 favelas que se espalhavam pelas montanhas que cercam Medellín e produziam o grosso da violência. Não havia poder público e, para subir lá, só com autorização. Numa operação de guerra, o Exército ocupou a região e instalou bases militares. Puderam, então, chegar educadores, assistentes sociais e policiais comunitários.

Com o policiamento comunitário, as pessoas se sentiram mais confortáveis para denunciar os matadores, o que diminuiu a sensação de impunidade. Não apenas se treinaram melhor os policiais, mas se capacitou a comunidade sobre como lidar com a questão da segurança.

Além das medidas repressivas, preventivas e educacionais, implementaram-se reformas urbanas nos bairros mais pobres, alguns deles nas montanhas, totalmente isolados. Construíram-se escadas, promoveu-se a coleta do lixo, escolas foram ampliadas, abriram centros de saúde e ofereceu-se um sistema de transporte como o teleférico, por exemplo.

Neste momento, foi construído numa das regiões mais pobres uma imensa biblioteca, em meio ao verde para servir de ponto de encontro tanto quanto de leitura. A ideia é que, em cada bairro, o principal centro seja uma biblioteca.

O método denominado Epidemiologia da Violência consistiu na observação do problema e a identificação de que se tratava, onde ocorria e a quem afetava, para assim, 
Artigo original

Hegemonia - Revista Eletrônica do Programa de Mestrado em Direitos Humanos, Cidadania e Violência/Ciência Política do Centro Universitário Unieuro

ISSN: $1809-1261$

UNIEURO, Brasília, número 24, Julho a Dezembro de 2018, pp. 93-109.

posteriormente formular as hipóteses dos possíveis fatores que interferiram, planejando intervenções e avaliando resultados.

Assim, foi possível identificar que em Cali os homicídios ocorriam principalmente durante os finais de semana, dias festivos e as sextas feiras que coincidiam com os dias de pagamento. Também foi possível determinar que mais de $25 \%$ das vítimas de homicídio estavam sob efeitos de drogas e que $80 \%$ das vítimas eram assassinadas por armas de fogo, segundo o Instituto de Medição e Avaliação da Saúde (IHME) da Universidade de Washington, dos Estados Unidos.

Uma Comissão foi criada sob a direção de um epidemiologista, com representantes da Polícia, Poder Judiciário, Medicina Legal, Saúde e Direitos Humanos. Este grupo realizou reuniões semanais, a fim de analisar e chegar a um consenso sobre as ocorrências de crime na semana anterior e para preparar um relatório para a Segurança Municipal. Uma das primeiras tarefas do grupo era chegar a uma definição operacional para cada uma das variáveis do crime. A comissão logo descobriu que os registros policiais incluíam apenas a contagem de corpos coletados por eles nas ruas; portanto, os feridos que morreram mais tarde no hospital não eram registrados. Além disso, de acordo com dados judiciais, os feridos fora Cali que tinham recebido assistência médica e morreram dentro dos limites da cidade eram contados como se o crime tivesse ocorrido em Cali.

A intensidade da violência em Medellín tem sido altamente dinâmica e episódica, mesmo que a taxas acima da média. Ele foi moldada por um complexo conjunto de atores, e estreitamente ligado à concorrência entre eles. No geral, Medellín tem sido afetada por um processo de transformação violência.

Medellín tem sido historicamente afetado por tráfico de armas, devido em grande parte a questões de história, geografia e economia política. Na verdade, Medellín é considerada um dos centros principais para a distribuição de armas de pequeno calibre e armas ligeiras no país. 
Artigo original

Hegemonia - Revista Eletrônica do Programa de Mestrado em Direitos Humanos, Cidadania e Violência/Ciência Política do Centro Universitário Unieuro

ISSN: $1809-1261$

UNIEURO, Brasília, número 24, Julho a Dezembro de 2018, pp. 93-109.

O deslocamento forçado é amplamente reconhecido como um mecanismo de controle territorial. Essa tática é usada extensivamente por atores armados locais em Medellín nos últimos cinco anos. Deslocamento forçado é de certa forma um mecanismo eficaz de controle territorial. Isso ocorre porque os homicídios são um indicador de segurança típico usado pelos governos para identificar as prioridades e organizar intervenções. Um aumento no número de homicídios tende a chamar a atenção das autoridades públicas e incitam respostas, que podem gerar custos para grupos armados.

\section{FATORES DE RISCO}

A sociedade tende a modelar respostas a conflitos por meio de atitudes culturais e crenças normativas. Regulamentos religiosos e morais em todas as sociedades são impedimentos poderosos de comportamento violento.

A literatura atual aponta para o fato de que o comportamento violento é um processo aprendido que começa nas primeiras fases de desenvolvimento psico-social. O comportamento dos pais e, numa fase posterior, o comportamento dos professores, são marcos importantes na determinação do comportamento violento.

Quando não há credibilidade da polícia ou do sistema jurídico, as respostas podem ir para a aplicação da justiça por própria mão. Estes valores culturais diferentes têm sido postulados como uma explicação para as diferenças de homicídios taxas entre o sul e o norte dos Estados Unidos.

O consumo excessivo de álcool, tem sido associado com elevadas taxas de homicídio. Por outro lado, políticas que restringem a venda de bebidas alcoólicas após determinadas horas à noite, têm demonstrado a redução dos homicídios em Cali e Bogotá, Colômbia (Centro de Referência Nacional Sobre Violência, 1994). 
Artigo original

Hegemonia - Revista Eletrônica do Programa de Mestrado em Direitos Humanos, Cidadania e Violência/Ciência Política do Centro Universitário Unieuro

ISSN: $1809-1261$

UNIEURO, Brasília, número 24, Julho a Dezembro de 2018, pp. 93-109.

No momento em que se forma, um adolescentes do ensino médio nos EUA, pode ter sido exposto a 18.000 assassinatos e 800 suicídios na tela da televisão. Para a Sociedade Americana de Psicologia, não há dúvida de que a violência na mídia estimula o comportamento violento, particularmente nos jovens (Donnerstein, Slaby, e Eron, 1994). A mídia também pode ensinar que a violência é uma forma normal de resolução de conflitos e também contribuem para a dessensibilização de crianças a atos violentos.

Parece não haver dúvida de que a proliferação de armas de fogo na população civil está associada ao aumento das taxas de homicídio. Nos EUA, armas de fogo causam $80 \%$ dos homicídios em jovens e o incremento observado em homicídios de jovens é devido a armas de fogo uma vez que os outros tipos de homicídios permaneceu constante (Carter Center, 1994).

A aquisição de uma arma tem sido associado com um aumento de quatro vezes no risco de o suicídio, por até seis anos após a compra (Wintemute et al., 1999). O controle no transporte de armas de fogo reduziu o número de homicídios em Cali e Bogotá (Centro de Referencia Nacional sobre violência, 1996; Villaveces et al, 2000).

\section{POLÍTICAS PÚBLICAS}

Um programa de desenvolvimento de micro-empresas foi realizada por toda a cidade para fornecer proprietários de pequenas empresas oficinas de formação em gestão de negócios, centros de formação orientada de trabalho foram estabelecidos para fornecer treinamento em habilidades específicas de acordo com a específica demanda de trabalho: carros e motos mecânica, cuidados com crianças e idosos, empregadas de hotel, restaurante garçons / garçonetes, os trabalhadores da indústria do vestuário, etc.

No início do mandato do prefeito, houve uma escassez de 25.000 aberturas da escola primária na cidade; 40.000 novas vagas foram criadas de tal forma que $100 \%$ de cobertura para o ensino primário público foi segurado para a próximapoucos anos. Melhoria da qualidade da educação através da criação de seis "Centros Didáticos" em bairros pobres: 
Artigo original

Hegemonia - Revista Eletrônica do Programa de Mestrado em Direitos Humanos, Cidadania e Violência/Ciência Política do Centro Universitário Unieuro

ISSN: $1809-1261$

UNIEURO, Brasília, número 24, Julho a Dezembro de 2018, pp. 93-109.

O maior projeto de habitação pública na história da Colômbia foi lançado através da construção de "Ciudadela Desepaz". Este é um projeto de desenvolvimento urbano para ajudar 28.000 famílias do salário mínimo construir a sua casa própria.

A produção de álcool é um monopólio e a principal fonte de receitas para os estados na Colômbia e álcool o consumo é um hábito colombiano cultural distinta para as celebrações. Dados epidemiológicos anteriores mostraram que a quase dois terços dos homicídios ocorreu durante tarde da noite e primeiras horas da manhã, especialmente durante fins de semana, e estudos de autópsias revelaram que $26 \%$ das vítimas de mortes violentas foram intoxicados com álcool. Por conta desses fatos, o governo municipal estabeleceu a lei seca, ordenando para fechar bares e discotecas.

Dados do DESEPAZ indicaram que as armas de fogo causaram cerca de $80 \%$ dos homicídios na cidade. Sendo assim, foi proibido o porte de armas de fogo, nessas ocasiões indicado pela análise epidemiológica descritiva. Por exemplo, durante a semana que coincidiram com a folha de pagamento pagamento, e em certas outras datas, como Dia das Mães, Dia das Bruxas, Natal e véspera de Ano Novo, o porte de armas de fogo foram proibidas.

Em um esforço para melhorar a eficácia dos agentes de aplicação da lei e restaurar a confiança entre eles e os cidadãos, foram implementados os seguintes projetos para melhoria da Polícia.

Embora tanto a polícia e as instituições do Judiciário são financiados e dirigidos pelo governo central, o município decidiu investir no seu desenvolvimento e melhoria no nível local. Como exemplo, funcionários de alto escalão da polícia que ganhavam salários magros, tinham que escolher entre muito baixa qualidade habitação para as suas famílias e aceitar a "oferta generosa" de casas caras ou apartamentos de senhores da droga, iniciando assim um processo de corrupção. Assim que esta situação foi identificada, o governo municipal iniciou 
Artigo original

Hegemonia - Revista Eletrônica do Programa de Mestrado em Direitos Humanos, Cidadania e Violência/Ciência Política do Centro Universitário Unieuro

ISSN: $1809-1261$

UNIEURO, Brasília, número 24, Julho a Dezembro de 2018, pp. 93-109.

umprograma, com a participação ativa do sector privado da cidade, para construir casas de qualidade boa o suficiente para a polícia.

Tendo estabelecido o fato de que cerca de cinquenta por cento dos oficiais de patrulha de rua não tinha concluído o ensino escola, o município iniciou um programa, com o apoio ativo das autoridades policiais de Bogotá, que permitiu todos os membros da polícia para completar sua escola dentro de dois anos.

Além disso, um programa especial de formação sobre direitos humanos, sobre a Constituição da Colômbia e em habilidades específicas relacionada com o seu trabalho, foi levada a cabo para melhorar o desempenho de agentes policiais

\section{RESULTADOS E DISCUSSÕES}

O pensamento tradicional na Colômbia atribuiu a violência à pobreza e, portanto, todos os esforços foram dirigidos para melhorar os pobres. A abordagem da saúde pública evita a discussão teórica sobre as causas da violência e se concentra no controle seus fatores de risco. Nem todos os fatores de risco são igualmente susceptíveis de tratamento e as prioridades têm de ser estabelecidas.

Medidas como o desarmamento de civis e restrições nos momentos em que o álcool poderia ser vendidos, não reduzir o taxa de homicídios total, mas não controlar a violência completamente. No entanto, os homicídios reduzindo permitir que a polícia e Judiciário para concentrar nesses fatores de risco que são os mais difíceis de tratar. Cali reduziu a absoluta número de homicídios por 600 entre 1994 e 1998 - uma redução substancial que permitiu o ataque a outra fatores, incluindo o crime organizado ou modificação de padrões culturais. Estes são fatores que requerem considerável recursos e esforço contínuo.

As mudanças constitucionais de 1991 devolveram poder às cidades ao redefinir o papel das prefeituras, que passaram a ter responsabilidades de monitorar e orientar as atividades da polícia. Por exemplo, em Cali, o prefeito Rodrigo Guerrero adotou medidas de controle da 
Artigo original

Hegemonia - Revista Eletrônica do Programa de Mestrado em Direitos Humanos, Cidadania e Violência/Ciência Política do Centro Universitário Unieuro

ISSN: $1809-1261$

UNIEURO, Brasília, número 24, Julho a Dezembro de 2018, pp. 93-109.

criminalidade baseadas em dados, utilizando evidências epidemiológicas. Apesar de ter produzido retornos modestos devido à falta de apoio político, a iniciativa ditou os rumos do debate sobre segurança cidadã no país. Em Bogotá, todos os prefeitos a partir de 1997 incluindo Antanas Mockus, Enrique Peñalosa e Luis Eduardo Gazon - repensaram políticas e programas de segurança pública.

Pela primeira vez, cidades adotaram iniciativas de policiamento comunitário eficientes e eficazes, focadas em áreas prioritárias (hotspots) e baseadas em métricas claras, ao lado do fechamento de bares e restrição ao consumo do álcool em determinados horários para diminuir a incidência de crimes de madrugada. Também melhoraram a mobilidade nas cidades e garantiram a manutenção e o uso dos espaços públicos, com a melhoria da iluminação e do calçamento das ruas.

Enquanto isso, os prefeitos de Medellín Luis Perez (2001-2003) e Sergio Fajardo (2003-2009) introduziram o conceito de urbanismo social e "acupuntura urbana", juntamente com princípios de transparência e tolerância zero com a corrupção. Projetos integrados de urbanismo congregaram esforços em torno da melhoria nas relações entre a administração local e a força policial nacional, assim como investimentos em espaços públicos nas comunidades e em áreas com altos índices de pobreza e violência. A oferta de serviços básicos - como escolas e bibliotecas -foi uma prioridade, tanto em áreas mais ricas centrais quanto nas mais pobres e afastadas.

Não há uma receita fixo para controlar a violência que pode ser aplicado em todos os contextos. Identificação do risco específico fatores que operam num determinado contexto é necessário.

\section{CONCLUSÕES E RECOMENDAÇÕES}

O governo colombiano foi o primeiro na região da América Latina e Caribe a introduzir novas formas de conter, prevenir e reduzir a violência. A experiência bem-sucedida da Colômbia na redução da violência se explica basicamente pelo alto grau de liderança e 
Artigo original

Hegemonia - Revista Eletrônica do Programa de Mestrado em Direitos Humanos, Cidadania e Violência/Ciência Política do Centro Universitário Unieuro

ISSN: $1809-1261$

UNIEURO, Brasília, número 24, Julho a Dezembro de 2018, pp. 93-109.

coerência dos governos locais em um contexto de reforma nacional. Tudo começou com as reformas constitucionais, em 1991, que restituíram o poder decisório às autoridades municipais, permitindo que prefeitos tivessem um papel-chave na prevenção da violência.

Entre outros fatores que explicam o sucesso do país no tema segurança cidadã está a instalação de sistemas de monitoramento da segurança e de criminalidade. Os sistemas facilitaram a alocação de recursos para áreas geográficas estratégicas, onde vivem as populações mais vulneráveis à violência, e os tornaram mais eficazes. Além disso, a combinação de medidas de controle com foco na prevenção social e situacional, dedicadas aos principais fatores de risco, contribuiu para aumentar a resiliência à violência. Essas medidas incluíram diferentes atores, como pesquisadores, sociedade civil e líderes comunitários, garantindo que as intervenções fossem coerentes com o contexto local e assegurando feedback que possibilitaram ajustes durante todo o processo de implementação.

As experiências aqui apresentadas oferecem um leque de inspirações e pontos de partida para a promoção da segurança cidadã. Elas ressaltam a importância de intervenções respaldadas por dados e informações, incluindo o papel crucial de definir e priorizar "hotspots" (manchas criminais), e pessoas e comportamentos de risco. Elas também mostram que esforços que busquem integrar os espaços urbanos formais e informais podem fazer diminuir a criminalidade. Um número de intervenções bem-sucedidas envolveu a preocupação com a retomada, pelas autoridades, do controle de territórios, seguidas de intervenções voltadas para os riscos socioeconômicos. A crença por trás dessa abordagem é a de que as autoridades devem ir além da garantia do cumprimento da lei, agindo sobre uma ampla gama de fatores econômicos e sociais que são determinantes para a insegurança e a percepção que se tem sobre ela. Em outros termos é uma importante fonte de inspiração para a formulação de politicas públicas no Brasil. 
Artigo original

Hegemonia - Revista Eletrônica do Programa de Mestrado em Direitos Humanos, Cidadania e Violência/Ciência Política do Centro Universitário Unieuro

ISSN: $1809-1261$

UNIEURO, Brasília, número 24, Julho a Dezembro de 2018, pp. 93-109.

\section{REFERÊNCIAS}

Castro, Manuel Fernando. La repuesta a lacriminalidad y la violencia en Colombia: Acciones del Estado para Promover la Convivencia y la Seguridad en las Ciudades. Disponível em: $<$ https://www.wilsoncenter.org/sites/default/files/Presentacion\%20Giraldo.pdf $>$. Acesso em 03 de outubro de 2016.

Cerda, Magdalena. Reducing Violence by Transforming Neighborhoods. Disponível em: <http://www.pubfacts.com/detail/22472117/Reducing-violence-by-transformingneighborhoods-a-natural-experiment-in-Medelln-Colombia>. Acesso em 03 de outubro de 2016.

Franco, Liliana Bernal. Urban violence and humanitarian action in Medellin. Disponível em: <http://cerac.org.co/assets/pdf/Other\%20publications/Hasow_6_Urban\%20violence\%20 and $\% 20$ humanitarian\%20action\%20in\%20Medellin_(6jun)_CN.pdf $>$. Acesso em 03 de outubro de 2016.

Guerrero, Rodrigo. An Epidemiological approach for the prevention of urban violence: The case of Cali, Colombia. Disponível em: <http://www.longwoods.com/content/17590>. Acesso em 03 de outubro de 2016.

Meija, Daniel. Un análisis de la criminalidad urbana en Colombia. Disponível em: <https://igarape.org.br/wp-content/uploads/2015/01/Criminalidad-urbana-en-Colombiadiciembre-2014.pdf>. Acesso em 03 de outubro de 2016.

Muggah, Robert. Tornando as cidades mais seguras: Inovações em segurança cidadã na América Latina. Disponível em: <https://igarape.org.br/tornando-as-cidades-maisseguras/>. Acesso em 03 de outubro de 2016.

Ramirez, Jorge Giraldo. Seguridad en Medellín: el éxito, sus explicaciones, limitaciones y fragilidades. Disponível em: $<$ https://www.wilsoncenter.org/sites/default/files/Presentacion\%20Giraldo.pdf $>$. Acesso em 03 de outubro de 2016. 